\title{
Determination of the Phenolic Composition and Antioxidant Activity of Pear Extracts
}

\author{
Mindaugas Liaudanskas, ${ }^{1}$ Kristina Zymonè, ${ }^{1}$ Jonas Viškelis, $^{2}$ \\ Almantas Klevinskas, ${ }^{1}$ and Valdimaras Janulis ${ }^{1}$ \\ ${ }^{1}$ Department of Pharmacognosy, Faculty of Pharmacy, Lithuanian University of Health Sciences, Sukileliu St. 13, \\ LT-44307 Kaunas, Lithuania \\ ${ }^{2}$ Institute of Horticulture, Lithuanian Research Centre for Agriculture and Forestry, Kauno St. 30, Babtai, \\ LT-54333 Kaunas, Lithuania \\ Correspondence should be addressed to Mindaugas Liaudanskas; m.liaudanskas@yahoo.com
}

Received 29 March 2017; Revised 28 July 2017; Accepted 16 September 2017; Published 12 November 2017

Academic Editor: Paula G. De Pinho

Copyright (c) 2017 Mindaugas Liaudanskas et al. This is an open access article distributed under the Creative Commons Attribution License, which permits unrestricted use, distribution, and reproduction in any medium, provided the original work is properly cited.

The specific HPLC analytical procedure was developed and validated for the determination of phenolic compounds in pear samples of different popular cultivars "Conference," "Concordia," "Grabova," and "Patten." HPLC mobile phase consisted of 0.05\% (v/v) trifluoroacetic acid in water and $100 \%(\mathrm{v} / \mathrm{v})$ acetonitrile. The HPLC method was used to identify and confirm the specificity of 8 analytes: chlorogenic acid, rutin, hyperoside, isoquercitrin, isorhamnetin rutinoside, quercitrin, quercitrin malonyl glucoside, and isorhamnetin glucoside. Repeatability \% RSD did not exceed 3.87\%, and intermediate precision did not exceed $4.63 \%$. The total content of phenolic compounds varied from $0.51 \pm 0.001 \mathrm{mg} / \mathrm{g}$ (cv. "Concordia") to $1.11 \pm 0.013 \mathrm{mg} / \mathrm{g}$ (cv. "Patten"). Chlorogenic acid was the major component in all the tested pear cultivars. The highest amount of chlorogenic acid $(0.69 \pm 0.033 \mathrm{mg} / \mathrm{g}) \mathrm{was}$ found in pear samples of the cultivar "Grabova," and the highest amount of flavonol compounds $(1.11 \pm 0.013 \mathrm{mg} / \mathrm{g})$ was found in pear samples of the cultivar "Concordia."

\section{Introduction}

Pears are among the most common fruit grown in Europe and worldwide. Approximately 3 million tonnes of pears per year are grown in the European Union alone [1], while almost 23 million tonnes of pears is grown per year in the world [2]. For this reason, pears are an important plant-based part of human diet both in Europe and in other continents. Various phenolic compounds have been detected in pear fruit-flavan-3-ols, flavonols, phenolic acids, anthocyanins, and so forth. Different groups of phenolic compounds as well as individual phenolic compounds have been found to have a specific effect on various physiological systems.

Phenolic compounds are an important group of plantbased biologically active compounds that strengthen the organism and prevent disease $[3,4]$. Phenolic compounds have a particularly strong antioxidant effect [5-7], which is closely related to the anti-inflammatory $[8,9]$ and anticancer [10-12] effect. Multiple epidemiologic studies have proven a significant correlation between the consumption of phenolic compound-rich food and a decreased risk for developing cardiovascular and neurodegenerative diseases $[13,14]$. Phenolic compounds have been proven to have a strong antimicrobial $[15,16]$ and antiviral $[17,18]$ effect. Based on abundant research data proving the beneficial effect of phenolic compounds in humans, it is appropriate to perform in-depth qualitative and quantitative analysis of the composition of phenolic compounds in pears.

A reliable analytical tool is required to achieve extensive results on phytochemical composition. HPLC methods for the determination of the qualitative and quantitative composition of phenolic compounds in pears were described in literature [19-21]. Based on these assumptions, extensive scientific research requires the redevelopment of sample 
preparation techniques and mobile phase gradients of those developed in other laboratories. Therefore, the objective was set to develop, optimise, and validate a suitable HPLC technique for the evaluation of phenolic compounds in pear samples grown in Lithuania.

\section{Materials and Methods}

2.1. Pears. The following pear cultivars were included in the study: "Conference"; "Concordia"; "Grabova”; and "Patten.". Pear samples were purchased in the supermarket. Each pear was cut into the slices of equal size (up to $1 \mathrm{~cm}$ in thickness), and the stalks and the seeds were removed. The pear slices were immediately dried in a drying oven at the temperature of $50^{\circ} \mathrm{C}$. Loss on drying before the analysis was determined by drying the dried pears in a laboratory drying oven to the complete evaporation of water and volatile compounds $\left(105^{\circ} \mathrm{C}\right.$ temperature; a difference in weight between the measurements was up to $0.01 \mathrm{~g}$ ) and by calculating the difference in raw material weight before and after drying [22]. The data were recalculated for absolute dry weight.

2.2. Chemicals. All the solvents, reagents, and standards used were of analytical grade. Acetonitrile and trifluoroacetic acids were obtained from Sigma-Aldrich $\mathrm{GmbH}$ (Buchs, Switzerland), and ethanol was obtained from Stumbras AB (Kaunas, Lithuania). Hyperoside ( $\geq 98 \%$ ), isoquercitrin ( $\geq 99 \%)$, rutin ( $\geq 99 \%)$, quercitrin $(\geq 98.5 \%)$, isorhamnetin-3O-rutinoside ( $\geq 99 \%)$, isorhamnetin glucoside $(\geq 95 \%)$, and chlorogenic acid ( $\geq 99 \%)$ standards were purchased from Extrasynthese (Genay, France). Quercetin-3-O-malonylglucoside $(\geq 85 \%)$, DPPH, 1,1-diphenyl-2-picrylhydrazyl, radical $(\leq 100 \%)$, ABTS, 2,2' -azinobis(3-ethylbenzothiazoline-6sulphonic acid) (>98\%), potassium persulphate $(99.99 \%)$, sodium acetate trihydrate ( $\geq 99 \%)$, iron (III) chloride hexahydrate ( $\geq 99 \%)$, and TPTZ (2,4,6-tripyridyl-s-triazine) ( $\geq 98 \%)$ were obtained from Sigma-Aldrich GmbH (Steinheim, Germany). Deionised water produced by the Crystal E HPLC (Adrona SIA, Riga, Latvia) water purification system was used.

2.3. Extraction. $2.5 \mathrm{~g}$ of milled dried pear (exact weight) was weighed, added to $30 \mathrm{~mL}$ of ethanol $(70 \%, \mathrm{v} / \mathrm{v})$, and extracted in a Sonorex Digital $10 \mathrm{P}$ ultrasonic bath (Bandelin Electronic $\mathrm{GmbH} \& \mathrm{Co}$. KG, Berlin, Germany) for 15 minutes at $60^{\circ} \mathrm{C}$. Ultrasound strength was $1100 \mathrm{~W}$, and frequency was $80 \mathrm{kHz}$. The extract obtained was filtered through a paper filter; the residue on the filter was washed twice with $10 \mathrm{~mL}$ of ethanol $(70 \%, v / v)$ in a $50 \mathrm{~mL}$ flask. The extract was filtered through a membrane filter with a pore size of $0.22 \mu \mathrm{m}$ (Carl Roth $\mathrm{GmbH}$, Karlsruhe, Germany).

2.4. Spectrophotometric Studies. All the spectrophotometric measurements were carried out with a double beam UV/VIS spectrophotometer M550 (Spectronic Camspec, Garforth, England, United Kingdom).

2.4.1. Determination of Total Phenolic Content. The total phenolic content (mg GAE/g DW) in the extracts of pears was determined by the Folin-Ciocalteu method [23], calculated from a gallic acid calibration curve, and expressed as $\mathrm{mg} / \mathrm{g}$ gallic acid equivalent (GAE) per gram of absolutely dry weight (DW) (mg GAE/g DW).

\subsubsection{Evaluation of Antioxidant Activity}

(1) $\mathrm{DPPH}^{\bullet}$ Free Radical Scavenging Assay. The DPPH free radical scavenging activity was evaluated using the method proposed by Brand-Williams et al. [24]. DPPH ${ }^{\bullet}$ solution in $96.3 \% \mathrm{v} / \mathrm{v}$ ethanol $\left(3 \mathrm{~mL}, 6 \times 10^{-5} \mathrm{M}\right)$ was mixed with $10 \mu \mathrm{L}$ of the ethanol extract of pear. A decrease in absorbance was determined at a wavelength of $515 \mathrm{~nm}$ after keeping the samples for 30 minutes in the dark.

(2) ABTS $^{\bullet+}$ Radical Cation Decolourisation Assay. An ABTS ${ }^{\bullet+}$ radical cation decolourisation assay was applied according to the methodology described by Re et al. [25]. A volume of $3 \mathrm{~mL}$ of $\mathrm{ABTS}^{\bullet+}$ solution (absorbance $0.800 \pm 0.02$ ) was mixed with $10 \mu \mathrm{L}$ of the ethanol extract of pear. A decrease in absorbance was measured at the wavelength of $734 \mathrm{~nm}$ after keeping the samples for 30 minutes in the dark.

(3) FRAP Assay. The ferric reducing antioxidant power (FRAP) assay was carried out as described by Benzie and Strain [26]. The working FRAP solution included TPTZ $(0.01 \mathrm{M}$ dissolved in $0.04 \mathrm{M} \mathrm{HCl}), \mathrm{FeCl}_{3} \times 6 \mathrm{H}_{2} \mathrm{O}(0.02 \mathrm{M}$ in water), and acetate buffer $(0.3 \mathrm{M}, \mathrm{pH} 3.6)$ at the ratio of $1: 1: 10$. A volume of $3 \mathrm{~mL}$ of a freshly prepared FRAP reagent was mixed with $10 \mu \mathrm{L}$ of the pear extract. An increase in absorbance was recorded after 30 minutes at the wavelength of $593 \mathrm{~nm}$.

(4) Calculation of Antioxidant Activity of the Pear Extracts. The antioxidant activity of the extracts was calculated from the Trolox calibration curve and expressed as $\mu \mathrm{mol}$ Trolox equivalent (TE) per gram of absolutely dry weight (DW). TE was calculated according to the following formula: TE $=c \times V / m(\mu \mathrm{mol} / \mathrm{g}), c$ being the concentration of Trolox established from the calibration curve (in $\mu \mathrm{M}$ ); $V$ being the volume of pear extract (in L); and $m$ being the weight (precise) of the raw plant material (in g).

2.5. Instrumentation and Chromatographic Conditions. A Waters 2695 chromatograph equipped with a Waters 2998 PDA detector (Waters, Milford, USA) was used for HPLC analysis. Chromatographic separation was managed, chromatograms were recorded, and data were processed with the Empower $^{\circledR}$ v. 3.0 software (Waters, Milford, USA). Chromatographic separation was carried out by using an ACE $(3 \mu \mathrm{m}, \mathrm{C} 18,150 \times 4.6 \mathrm{~mm}$ i.d.) column equipped with an ACE $\left(3 \mu \mathrm{m}, \mathrm{C}_{18}\right)$ precolumn (Advanced Chromatography Technologies, Aberdeen, Scotland). The column was operated at a constant temperature of $40^{\circ} \mathrm{C}$. The volume of the extract being investigated was $10 \mu \mathrm{L}$. The flow rate was $1 \mathrm{~mL} / \mathrm{min}$, and gradient elution was used. The mobile phase consisted of $0.05 \%(\mathrm{v} / \mathrm{v})$ trifluoroacetic acid in water (solvent $\mathrm{A}$ ) and $100 \%(\mathrm{v} / \mathrm{v})$ acetonitrile (solvent B). The following conditions of elution were applied: 0-38 minutes, $14-23 \%$ B; 38-39 
minutes, 23-90\% B; 39-44 minutes, 90\% B (isocratic elution); and 44-45 minutes, $90-14 \%$ B. The identification of the chromatographic peaks was achieved by comparing the retention times and spectral characteristics $(\lambda=200-400 \mathrm{~nm})$ of the eluting peaks with those of the reference compounds. The compounds identified were confirmed by spiking the sample with the standard compound and monitoring the changes in the peak shape and spectral characteristics. For quantitative analysis, a calibration curve was obtained by injection of known concentrations of different standard compounds. The concentrations of phenolic compounds identified in the pear extracts were within the limits of the calibration curves. Chlorogenic acid was quantified at $325 \mathrm{~nm}$, and flavonols were quantified at $350 \mathrm{~nm}$.

2.6. Statistical Data Analysis. All the experiments were carried out in triplicate. Means and standard deviations were calculated using computer software Microsoft Office Excel 2013 (Microsoft, Redmond, Washington, USA) and SPSS 20.0 (Chicago, Illinois, USA). A single factor analysis of variance (ANOVA) along with the post hoc Tukey test was employed for statistical analysis. The correlation was evaluated by Spearman's analysis. Differences were considered to be significant at $p<0.05$.

\section{Results and Discussion}

3.1. Selection of the Extraction Technique. The selection of the solvent and the conditions of extraction is an important analytical step in the development of the technique for the qualitative and quantitative analysis of the biologically active compounds in raw plant material. The solvent of the extraction is one of the main factors in the prognosis of the qualitative and quantitative composition of the isolated phenolic compounds [27-29].

During the first stage of the investigation for the selection of the conditions of extraction, we evaluated the influence of ethanol at various concentrations (20-96\%) on the extraction of phenolic compounds from pear fruit samples. The obtained results showed that the greatest total amount of phenolic compounds $(6.36 \pm 0.23 \mathrm{mg} \mathrm{GAE} / \mathrm{g}, p<0.05)$ was obtained from pear fruit samples by applying extraction with $70 \%(\mathrm{v} / \mathrm{v})$ ethanol, and thus this concentration of ethanol was selected for further studies (Figure 1).

During the second stage of the investigation for the selection of the conditions of extraction, we evaluated the influence of various temperatures $\left(20-70^{\circ} \mathrm{C}\right)$ on the extraction of phenolic compounds from pear fruit samples. The greatest total amount of phenolic compounds $(4.63 \pm 0.10 \mathrm{mg}$ GAE/g, $p<0.05$ ) was obtained by extracting fruit samples at the temperature of $60^{\circ} \mathrm{C}$ (Figure 2), and thus this temperature was selected for further studies.

During the third stage of the investigation for the selection of the conditions of extraction, we evaluated the influence of the duration of the extraction on the extraction of phenolic compounds from pear fruit samples. The results of the experiments showed that the greatest total amount of phenolic compounds $(5.18 \pm 0.18 \mathrm{mg} \mathrm{GAE} / \mathrm{g}, p<0.05)$ was obtained by extracting fruit samples in an ultrasonic bath for

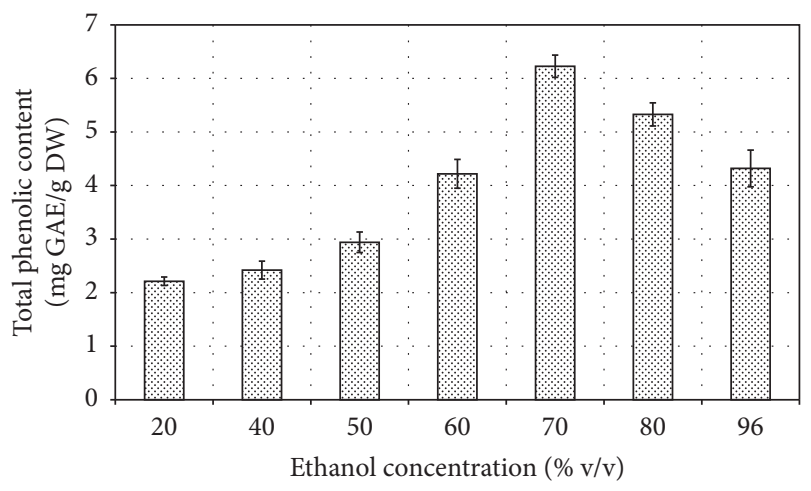

FIGURE 1: Effect of the concentration of the extractant on the extraction output of phenolic compounds from pear fruit samples.

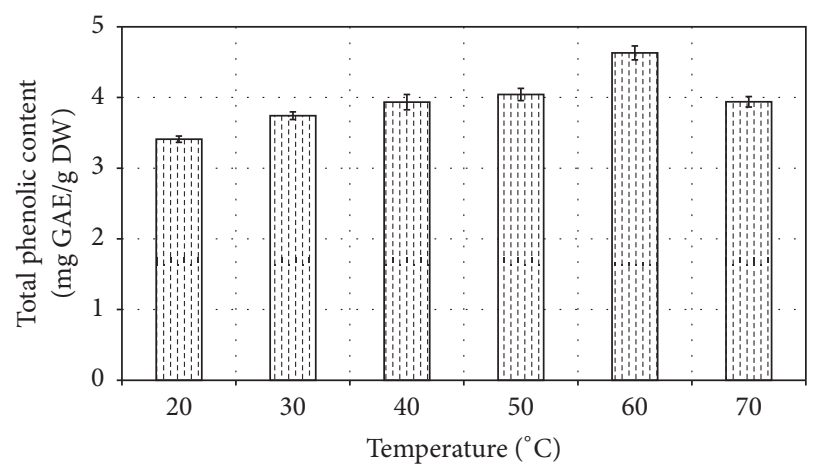

FIGURE 2: Effect of different temperatures on the extraction output of phenolic compounds from pear fruit samples.

15 min (Figure 3). For this reason, this duration of extraction was selected for further studies.

Summing up the results of the experiments for the selection of the extraction technique, the greatest output of phenolic compounds from pear fruit samples was obtained by extracting this raw plant material in $70 \%$ ethanol for $15 \mathrm{~min}$ in an ultrasonic bath at the temperature of $60^{\circ} \mathrm{C}$. Based on these results, these conditions of extraction were selected for further studies.

3.2. Development and Optimisation of Chromatographic Separation. It is especially important to select the optimal analytical column for the analysis of the raw plant material. Currently, reversed-phase C18 columns are most common for the analysis of phenolic compounds [27, 30]. Reversed-phase HPLC uses C18 or other alkyl-chains [31]. Silicon dioxide or polyamide chains are also used [32]. Usually, the column length varies from 100 to $300 \mathrm{~mm}$ [31].

We performed tests to determine the best analyte peak resolution and the separation of the phenolic compound mixture. Selectivity and resolution of two differently sized chromatographic columns filled with different sorbents were evaluated: ACE C18 $(150 \mathrm{~mm} \times 4.6 \mathrm{~mm}, 3 \mu \mathrm{m})$ and YMC C18 $(250 \mathrm{~mm} \times 4.6 \mathrm{~mm}, 5 \mu \mathrm{m})$. Best selectivity and resolution were achieved using ACE C18 $(150 \mathrm{~mm} \times 4.6 \mathrm{~mm}, 3 \mu \mathrm{m})$; therefore, this column was selected for further studies. 


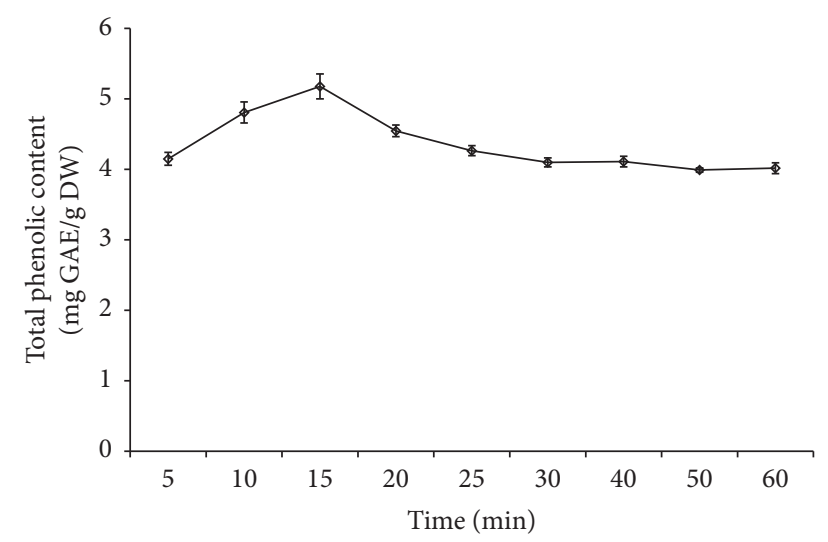

FIGURE 3: Effect of different duration of extraction on the extraction output of phenolic compounds from pear fruit samples.

In phenolic compound analysis, mobile phase usually consists of water and organic component solvent (usually acetonitrile or methanol) [31]. In order to reduce peak asymmetry (the spread of the analyte concentration zone), eluents may be acidified [27]. In order to achieve optimal analyte separation, we performed tests where the mobile phase was $0.05 \%$ trifluoroacetic acid and acetonitrile. The gradient elution method was optimised in order to achieve sufficient resolution for quantitative analysis (Figure S1, in Supplementary Material available online at https://doi.org/10.1155/2017/7856521). We performed experiments with different flow speed of the mobile phase (Figure S2) and different temperature (Figure S3), and we optimised the mobile phase gradient. Temperature affects separation, and, in order to ensure repeatability, it is recommended to maintain constant column temperature [27]; therefore, the column was placed in a thermostat during the analysis, and the impact of temperature on the efficacy of phenolic compound separation was evaluated. By applying conditions described in Section 2.4, we efficiently separated flavonoid glycoside and phenolic acid complex (quercetin and isorhamnetin glycoside and chlorogenic acid) from pear fruit extracts. The analyte peak resolution of the analysed extracts was higher than 2, which allows for performing qualitative and quantitative analysis of biologically active compounds. Salta et al. [19] described a shorter method (duration, $25 \mathrm{~min}$ ), but it only allows for evaluating the quantitative composition of phenolic acids, flavan-3-ols. Escarpa and González [20, 33] developed a 25-minute HPLC method, but it allowed for separating 10 analytes. Our samples have a higher number of analytes, and this method failed to separate them properly.

The chromatogram of the ethanol extracts of pear samples is depicted in Figure 4. In our study, the elution order of the identified analytes was as follows: chlorogenic acid, quercetin-3-O-rutinoside (rutin), quercetin-3$O$-galactoside (hyperoside), quercetin-3-O-glucoside (isoquercitrin), QMG, isorhamnetin rutinoside, quercetin-3-Orhamnoside (quercitrin), and isorhamnetin glucoside.

3.3. Validation of the Method. Validation of the method was performed based on the ICH recommendations [34].

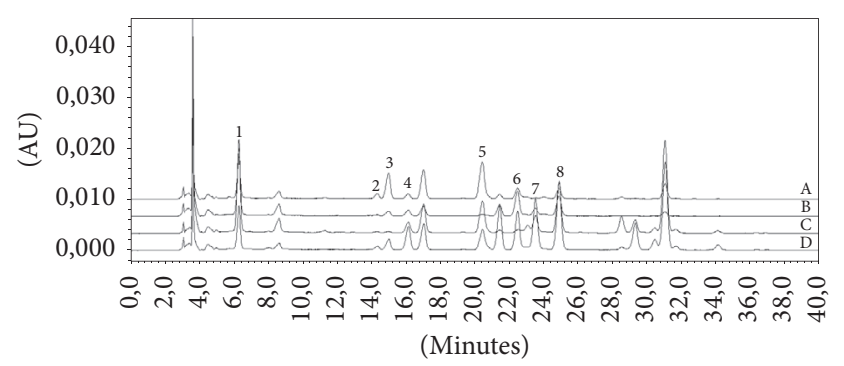

FIGURE 4: Chromatograms of the investigated pear sample extracts, $\lambda=360 \mathrm{~nm}$. The uppercase letters denote different pear cultivars: A: "Patten"; B: "Conference"; C: "Grabova"; and D: "Concorde." Numbers indicate the peaks of analytes: 1: chlorogenic acid; 2 : quercetin-3-O-rutinoside (rutin); 3: quercetin-3-O-galactoside (hyperoside); 4: quercetin-3-O-glucoside (isoquercitrin); 5: quercetin-3-O-malonylglucoside; 6: isorhamnetin rutinoside; 7: quercetin-3-O-rhamnoside (quercitrin); and 8: isorhamnetin glucoside.

The following characteristics of validation were evaluated: the specificity of the method, precision (repeatability and intermediate precision), detection and quantitation limits of the analytes, and linearity.

The evaluation of the specificity of the method for peak identification and purity was based on the comparison of retention times and UV spectra of the analytes with those of the standard compounds. The compounds identified were confirmed by adding the standard compound into the analysed extract and monitoring the changes in the peak shape and spectral characteristics.

The quantitation limit of analytes was assessed by comparing the peak height to the baseline noise. The ratio of the peak height to baseline noise (signal-to-noise ratio) used for the estimation of the detection limit was $3: 1$, and the quantitation limit was $10: 1$. The determined limit of detection (LOD) varied from $0.021 \mu \mathrm{g} / \mathrm{mL}$ (chlorogenic acid) to $0.224 \mu \mathrm{g} / \mathrm{mL}$ (rutin). The limit of quantitation varied from $0.070 \mu \mathrm{g} / \mathrm{mL}$ (chlorogenic acid) to $0.747 \mu \mathrm{g} / \mathrm{mL}$ (rutin). The results obtained confirm that this method can be used for the quantitative analysis of phenolic compounds. The estimated determination coefficients $\left(R^{2}\right)$ of the calibration curves were greater than 0.9989 , and this proves the linearity of the quantitative evaluation method (Table 1).

Precision of the HPLC method was assessed based on two parameters: repeatability and intermediate precision. The obtained results describing the precision of our selfdeveloped HPLC method are summarised in Table 2. The evaluation of result repeatability was based on the results of consecutive analyses performed within the same day (6 consecutive analyses of a mixture of standards at 3 different concentrations performed within the same day). The percent relative standard deviation (\% RSD) of the method repeatability, determined according to the peak area, varied from $1.22 \%$ (chlorogenic acid) to $1.52 \%$ ((-)-epicatechin). Concentrations of reference compounds used in repeatability assessment are shown in Table S1. The intermediate precision of the results was assessed based on the results of analyses performed 
TABLE 1: Characteristics of the quantitative evaluation of phenolic compounds.

\begin{tabular}{|c|c|c|c|c|}
\hline Compound & $\begin{array}{c}\text { Confirmed linearity } \\
\text { range }(\mu \mathrm{g} / \mathrm{mL})\end{array}$ & $\begin{array}{c}\text { LOD } \\
(\mu \mathrm{g} / \mathrm{mL})\end{array}$ & $\begin{array}{c}\text { LOQ } \\
(\mu \mathrm{g} / \mathrm{mL})\end{array}$ & $R^{2}$ \\
\hline Chlorogenic acid & $0.1-10$ & 0.021 & 0.07 & 0.9998 \\
\hline Rutin & $1.6-25$ & 0.224 & 0.75 & 0.9999 \\
\hline Hyperoside & $2.5-40$ & 0.068 & 0.22 & 0.9999 \\
\hline Isoquercitrin & $1.4-22$ & 0.080 & 0.27 & 0.9989 \\
\hline QMG & $1.1-17$ & 0.119 & 0.400 & 0.9998 \\
\hline Isorhamnetin rutinoside & $0.8-50$ & 0.112 & 0.38 & 0.9999 \\
\hline Quercitrin & $2.5-40$ & 0.072 & 0.24 & 0.9999 \\
\hline Isorhamnetin glucoside & $0.8-100$ & 0.089 & 0.300 & 0.9999 \\
\hline
\end{tabular}

TABle 2: Precision of the HPLC method for the quantitative determination of phenolic compounds.

\begin{tabular}{|c|c|c|c|c|}
\hline \multirow{3}{*}{ Compound } & \multicolumn{4}{|c|}{ Relative standard deviation (\%) for the peak area } \\
\hline & \multirow[b]{2}{*}{ 1st concentration } & \multicolumn{2}{|c|}{ Intraday $^{\mathrm{a}}$} & \multirow{2}{*}{ Interday $^{\mathrm{b}}$} \\
\hline & & 2nd concentration & 3rd concentration & \\
\hline Chlorogenic acid & 0.33 & 0.89 & 3.39 & 4.48 \\
\hline Rutin & 0.45 & 1.09 & 3.87 & 4.63 \\
\hline Hyperoside & 0.33 & 0.4 & 0.46 & 3.4 \\
\hline Isoquercitrin & 0.15 & 1.61 & 2.99 & 2.76 \\
\hline QMG & 0.45 & 0.75 & 2.67 & 4.29 \\
\hline Isorhamnetin rutinoside & 0.36 & 0.72 & 3.15 & 0.79 \\
\hline Quercitrin & 0.65 & 0.52 & 2.53 & 1.16 \\
\hline Isorhamnetin glucoside & 0.56 & 0.80 & 2.49 & 2.4 \\
\hline
\end{tabular}

${ }^{\mathrm{a}}$ Repeatability. ${ }^{\mathrm{b}}$ Intermediate precision.

within 3 different days ( 6 consecutive analyses of a mixture of standards at the mean concentration performed within the same day; 18 analyses in total), and its \% RSD for the peak area varied from $0.79 \%$ (isorhamnetin rutinoside) to $4.63 \%$ (rutin).

3.4. Identification of Phenolic Compounds in the Analysed Pear Samples. In this study, the developed, optimised, and validated HPLC method was applied to investigate the ethanol extracts of pear samples. The content of phenolic compounds in the pear of cultivars "Conference"; "Concordia"; "Grabova"; and "Patten" was analysed qualitatively and quantitatively. The chromatograms of the tested pear cultivars are shown in Figure 4, and Table 3 summarises the characteristics of the quantitative content.

Chlorogenic acid was the major component of the identified phenolic compounds in all tested pear cultivars. Chlorogenic acid has properties that are beneficial for human health: besides antioxidant activity [35] and an anti-inflammatory effect [36], it lowers the risk of type II diabetes mellitus [37], improves cardiac and vascular function [38], and inhibits carcinogenesis processes [39, 40]. Other scientists [41, 42] also have detected chlorogenic acid in pear fruit.

The pears of the cv. "Grabova" contained the highest amount of chlorogenic acid $(0.69 \pm 0.033 \mathrm{mg} / \mathrm{g})$, and this amount was 2.16-fold greater than the lowest amount of this acid $(0.32 \pm 0.005 \mathrm{mg} / \mathrm{g})$ found in the pear samples of the cultivar "Patten" (Table 3 ). Our results confirm the findings of other studies indicating that chlorogenic acid is one of the most common phenolic compounds in pears [42-44]. Salta et al. [19] detected 4.3-62.4 mg/100 g FW of chlorogenic acid in fruit of the analysed pear cultivars.

In the investigated ethanol extracts of pear samples, flavonol compounds (quercetin and isorhamnetin glycosides) were the most abundant group of phenolic compounds. The consumption of products rich in quercetin glycosides reduces the risk of cancer and neurodegenerative diseases [ 45 , 46]. Quercetin glycosides inhibit the angiotensin-converting enzyme and thus have an antihypertensive effect [47].

The following flavonol derivatives were identified and evaluated quantitatively: rutin, hyperoside, isoquercitrin, quercetin malonyl glucoside, quercitrin, isorhamnetin rutinoside, and isorhamnetin glucoside. Kolniak-Ostek and Oszmiański [41] also identified rutin, hyperoside, isoquercitrin, isorhamnetin rutinoside, and isorhamnetin glucoside in pear fruit. These scientists identified all three quercetin glycosides and isorhamnetin glucoside in pear peels, rutin, isoquercitrin, and isorhamnetin rutinoside in the pulp and hyperoside, isoquercitrin, and both isorhamnetin glycosides in seeds. Lin and Harnly [42] who analysed fruit peels of various pear cultivars have also identified quercetin malonyl glucoside in addition to rutin, hyperoside, and isoquercitrin. In their study, quercetin malonyl glucoside was not detected in all the analysed pear samples, as it was in our case as well. In our analysed samples, quercetin malonyl glucoside was not detected in pear samples of the cultivar "Conference," 
TABLE 3: Content of phenolic compounds in ethanol extracts obtained from pears (expressed for absolute dry lyophilisate weight).

\begin{tabular}{|c|c|c|c|c|}
\hline \multirow{2}{*}{ Compound } & \multicolumn{4}{|c|}{ Amount of phenolic compounds in different cultivars ${ }^{\mathrm{a}}, \mathrm{mg} / \mathrm{g}$} \\
\hline & "Conference" & "Concordia" & "Grabova” & "Patten" \\
\hline Chlorogenic acid & $0.53 \pm 0.007^{\mathrm{b}}$ & $0.66 \pm 0.011^{\mathrm{a}}$ & $0.69 \pm 0.033^{\mathrm{a}}$ & $0.32 \pm 0.005^{\mathrm{c}}$ \\
\hline Rutin & $0.01 \pm 0.001^{\mathrm{c}}$ & $0.03 \pm 0.007^{\mathrm{b}}$ & $<$ LLOD & $0.09 \pm 0.001^{\mathrm{a}}$ \\
\hline Hyperoside & $0.02 \pm 0.002^{\mathrm{b}}$ & $0.06 \pm 0.009^{\mathrm{a}}$ & $0.03 \pm 0.002^{\mathrm{b}}$ & $0.02 \pm 0.0003^{\mathrm{b}}$ \\
\hline Isoquercitrin & $0.04 \pm 0.001^{\mathrm{c}}$ & $0.08 \pm 0.004^{\mathrm{a}}$ & $0.07 \pm 0.006^{\mathrm{b}}$ & $0.07 \pm 0.001^{\mathrm{b}}$ \\
\hline QMG & $<$ LLOD & $0.07 \pm 0.004^{\mathrm{c}}$ & $0.09 \pm 0.012^{\mathrm{b}}$ & $0.12 \pm 0.004^{\mathrm{a}}$ \\
\hline Isorhamnetin rutinoside & $0.05 \pm 0.001^{\mathrm{b}}$ & $0.08 \pm 0.011^{\mathrm{a}}$ & $0.01 \pm 0.001^{\mathrm{c}}$ & $0.02 \pm 0.0001^{\mathrm{c}}$ \\
\hline Quercitrin & $0.02 \pm 0.004^{\mathrm{c}}$ & $0.09 \pm 0.002^{\mathrm{a}}$ & $0.03 \pm 0.003^{b}$ & $<$ LLOD \\
\hline Isorhamnetin glucoside & $0.03 \pm 0.004^{\mathrm{c}}$ & $0.12 \pm 0.004^{\mathrm{a}}$ & $0.08 \pm 0.009^{b}$ & $0.02 \pm 0.001^{c}$ \\
\hline Total & $0.71 \pm 0.011^{\mathrm{c}}$ & $1.18 \pm 0.013^{\mathrm{a}}$ & $1.00 \pm 0.013^{\mathrm{b}}$ & $0.66 \pm 0.001^{\mathrm{d}}$ \\
\hline
\end{tabular}

${ }^{a}$ Values are means $(n=3)$. The different letters indicate significant differences between the values $(p<0.05)$.

and rutin was not detected in pear samples of the cultivar "Grabova." Other scientists also failed to detect rutin in any of the pear samples of the analysed cultivars [42]. The total amount of the identified flavonol compounds in pear samples of the analysed cultivars varied from $0.17 \pm 0.004 \mathrm{mg} / \mathrm{g}$ (cv. "Conference") to $0.22 \pm 0.002 \mathrm{mg} / \mathrm{g}$ ("Grabova"). The highest amounts of hyperoside, isoquercitrin, isorhamnetin rutinoside, quercitrin, and isorhamnetin glucoside were detected in pear samples of the cultivar "Concordia," and the highest amounts of rutin and quercetin malonyl glucoside were detected in pear samples of the cultivar "Patten."

Our analysis showed a wide variation in the phenolic content between different pear cultivars. The total content of phenolic compounds identified in the ethanol extracts of pear samples ranged from $0.51 \pm 0.001 \mathrm{mg} / \mathrm{g}$ (cv. "Concordia") to $1.11 \pm 0.013 \mathrm{mg} / \mathrm{g}$ (cv. "Patten").

The analysis of the qualitative and quantitative composition of pear cultivars showed that the cultivar itself as a factor had an impact on the parameters of qualitative and quantitative content of phenolic compounds in pears, and, depending on the pear cultivar, these parameters could vary considerably. The highest amount of the identified phenolic compounds was detected in pear samples of the cultivar "Concordia," and, therefore, upon completion of more indepth agrotechnical studies, pears of this cultivar could potentially be beneficial for a wider cultivation in commercial and amateur gardens.

\subsection{Measurements of Antioxidant Activity in Pear Extracts.} After studying the qualitative and quantitative composition of phenolic compounds of pears of different cultivars, it was important to examine and assess the antiradical and reduction activity in the pear extracts. The results obtained during studies will be useful for the selection of pear cultivars in order to provide consumers with products rich in antioxidants and will allow for predicting the antioxidant effect of pear extracts in vivo.

In order to thoroughly evaluate the antioxidant activity of the pear extracts, different antioxidant capacity assays (DPPH, ABTS, and FRAP) were employed. The results of in

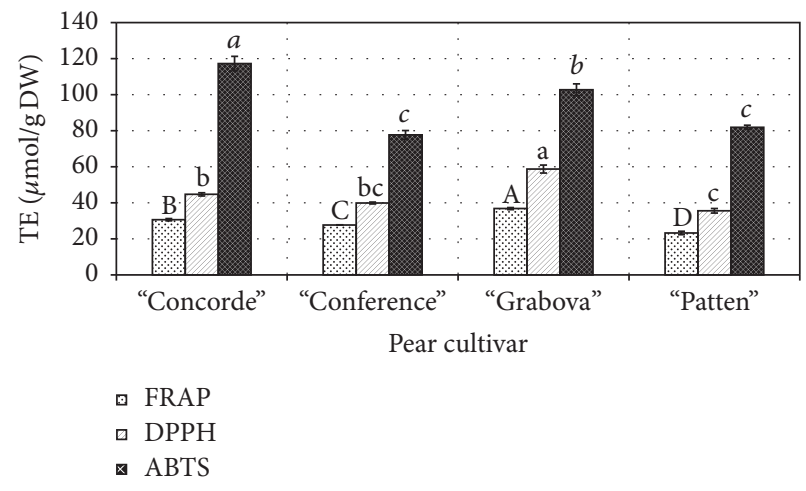

FIGURE 5: The antioxidant activity of pear extracts determined by using DPPH, ABTS, and FRAP assays. Values are means, and error bars indicate standard deviations $(n=3)$. The different letters indicate significant differences in the values between pear cultivars $(p<0.05)$.

vitro evaluation of antioxidant activity in the pear extracts (cultivars "Concorde," "Conference," "Grabova," and "Patten") are summarised in Figure 5.

After evaluating the antioxidant activity of pear extracts examined in vitro by FRAP and DPPH UV-VIS spectrophotometric assays, the strongest antioxidant activity was detected in pear extracts of the "Grabova" cultivar (resp., $36.86 \pm$ $0.59 \mu \mathrm{mol} / \mathrm{g}$ and $58.75 \pm 2.23, p<0.05)$. Meanwhile, the ABTS method showed that the highest antiradical activity in vitro $(117.29 \pm 3.96 \mu \mathrm{mol} / \mathrm{g}, p<0.05)$ was in the "Concorde" cultivar pear extracts.

To our knowledge, there are very few studies on the antioxidant activity of pears. For this reason-and due to the differences in the applied research methods-it is difficult to compare our results with those obtained by other scientists. Therefore, the findings from this study on the antioxidant activity of pear extracts in vitro were compared with those obtained in studies on other plants belonging to the Rosaceae family. The total reducing activity in apple extract samples was established by the UV-VIS spectrophotometric FRAP method in vitro and averaged $117.13 \mu \mathrm{mol} / \mathrm{g}$ DW [48], and 
it was by 3.2-5.0 times more potent than the reducing activity of pear fruit extract. Such differences could have been influenced by the differences in the qualitative and quantitative composition of pear and apple fruit, which was determined not only by different genus factors but also by various other factors (composition of the soil, the climaticmeteorological, cultivation, or storage conditions, orchard fertigation, etc.) that influence the chemical composition of pears. We did not evaluate them in this study. The extracts obtained from the fruit of different Sorbus species by DPPH and FRAP showed a higher antioxidant activity; that is, the TE values were higher than those determined in the present study: $86.9-181.1 \mu \mathrm{moL} / \mathrm{g}$ DW by the DPPH assay and 221.1-396.0 $\mu \mathrm{moL} / \mathrm{g}$ DW by the FRAP assay. These differences could be due to the intermediate differences between the chemical composition of pears and rowan and the influence of other factors. The results of antiradical activity studies on different types of rowan berries were obtained using the ABTS method and are similar to our results. They varied from $65.3 \mu \mathrm{moL} / \mathrm{g}$ DW to $131.1 \mu \mathrm{moL} / \mathrm{g} \mathrm{DW}$ [49].

After performing correlation analysis there was a very strong positive correlation between antioxidant activity and the content of chlorogenic acid (DPPH: 0.999, $p<0.01$; FRAP: $0.999, p<0.01)$. No more statistically significant correlation was found between individual identified phenolic compound and the total antioxidant activity of sampled extracts in vitro.

\section{Conclusions}

The HPLC-based analytical procedure for the detection and evaluation of phenolic compounds in pear samples of 4 popular cultivars was optimised and validated. The specificity, precision, and assay range confirmed the suitability of this method.

The distribution of 8 phenolic compounds was determined in the tested pear samples. Chlorogenic acid was the major component in the samples of all the tested cultivars. The highest amounts of chlorogenic acid were detected in pear samples of the cultivar "Grabova," and the highest amounts of flavonol compounds were detected in pear samples of the cultivar "Concordia."

The highest antioxidant activity in vitro measured using the DPPH and FRAP methods was found in pear extracts of the "Grabova" cultivar, and the highest antioxidant activity in vitro measured with the ABTS method was found in the "Concorde" cultivar extracts.

\section{Abbreviations}
cv:: Cultivar
DW: Dry weight
GAE: Gallic acid equivalent
HPLC: High-performance liquid chromatography
LLOD: Lower than limit of detection
PDA: Photodiode array
QMG: Quercetin malonyl glucoside
$\%$ RSD: Percent relative standard deviation
v/v: Volume/volume.

\section{Conflicts of Interest}

The authors declare that there are no conflicts of interest regarding the publication of this paper.

\section{References}

[1] EU-27, "Fresh Deciduous Fruit Annual. Good Prospects for EU27 Apple and Pear Production. Global Agriculture Information Network," GAIN Report Network: E60062.

[2] "Data from THE WORLD APPLE AND PEAR ASSOCIATION. Available from the internet," http://www.wapa-association.org/asp/page_1.asp.

[3] H. El Gharras, "Polyphenols: food sources, properties and applications-a review," International Journal of Food Science \& Technology, vol. 44, no. 12, pp. 2512-2518, 2009.

[4] J. Sun, Y.-F. Chu, X. Wu, and R. H. Liu, "Antioxidant and antiproliferative activities of common fruits," Journal of Agricultural and Food Chemistry, vol. 50, no. 25, pp. 7449-7454, 2002.

[5] A. Scalbert, I. T. Johnson, and M. Saltmarsh, "Polyphenols: antioxidants and beyond," American Journal of Clinical Nutrition, vol. 81, no. 1, pp. 215S-217S, 2005.

[6] K. B. Pandey and S. I. Rizvi, "Plant polyphenols as dietary antioxidants in human health and disease," Oxidative Medicine and Cellular Longevity, vol. 2, no. 5, pp. 270-278, 2009.

[7] R. C. Hider, Z. D. Liu, and H. H. Khodr, "Metal chelation of polyphenols," Methods in Enzymology, vol. 335, pp. 190-203, 2001.

[8] A. W. Boots, L. C. Wilms, E. L. R. Swennen, J. C. S. Kleinjans, A. Bast, and G. R. M. M. Haenen, "In vitro and ex vivo anti-inflammatory activity of quercetin in healthy volunteers," Nutrition Journal, vol. 24, no. 7-8, pp. 703-710, 2008.

[9] S. Pastore, A. Potapovich, V. Kostyuk et al., "Plant polyphenols effectively protect $\mathrm{HaCaT}$ cells from ultraviolet C-triggered necrosis and suppress inflammatory chemokine expression," Annals of the New York Academy of Sciences, vol. 1171, pp. 305313, 2009.

[10] C. Kandaswami, L. T. Lee, P. P. Lee et al., "The antitumor activities of flavonoids," In Vivo, vol. 19, no. 5, pp. 895-909, 2005.

[11] P. Lakhanpal and D. K. Rai, "Quercetin: A Versatile Flavonoid," Internet Journal of Medical Update, vol. 2, no. 2, pp. 22-37, 2007.

[12] M. López-Lázaro, "Flavonoids as anticancer agents: Structureactivity relationship study," Current Medicinal Chemistry - AntiCancer Agents, vol. 2, no. 6, pp. 691-714, 2002.

[13] E. Weichselbaum, L. Wyness, and S. Stanner, "Apple polyphenols and cardiovascular disease - a review of the evidence," Nutrition Bulletin, vol. 35, no. 2, pp. 92-101, 2010.

[14] J. P. E. Spencer, "The impact of fruit flavonoids on memory and cognition," British Journal of Nutrition, vol. 104, no. 3, pp. S40S47, 2010

[15] L. J. Nohynek, H.-L. Alakomi, M. P. Kähkönen et al., "Berry phenolics: antimicrobial properties and mechanisms of action against severe human pathogens," Nutrition and Cancer, vol. 54, no. 1, pp. 18-32, 2006.

[16] T. P. Cushnie and A. J. Lamb, "Antimicrobial activity of flavonoids," International Journal of Antimicrobial Agents, vol. 26, no. 5, pp. 343-356, 2005.

[17] J. H. Chávez, P. C. Leal, R. A. Yunes et al., "Evaluation of antiviral activity of phenolic compounds and derivatives against rabies virus," Veterinary Microbiology, vol. 116, no. 1-3, pp. 53-59, 2006. 
[18] K. Likhitwitayawuid, B. Supudompol, B. Sritularak, V. Lipipun, K. Rapp, and R. F. Schinazi, "Phenolics with anti-HSV and antiHIV activities from Artocarpus gomezianus, Mallotus pallidus, and Triphasia trifolia," Pharmaceutical Biology, vol. 43, no. 8, pp. 651-657, 2005.

[19] J. Salta, A. Martins, R. G. Santos et al., "Phenolic composition and antioxidant activity of Rocha pear and other pear cultivars - A comparative study," Journal of Functional Foods, vol. 2, no. 2, pp. 153-157, 2010.

[20] A. Escarpa and M. C. González, "Fast separation of (poly)phenolic compounds from apples and pears by high-performance liquid chromatography with diode-array detection," Journal of Chromatography A, vol. 830, no. 2, pp. 301-309, 1999.

[21] M. G. L. Hertog, E. J. M. Feskens, and P. C. H. Hollman, "Content of potentially anticarcinogenic flavonoids of 28 vegetables and 9 fruits commonly consumed in the Netherlands," Journal of Agricultural and Food Chemistry, vol. 40, no. 12, pp. 23792383, 1992.

[22] European pharmacopoeia, Council of Europe: Strasbourg, 7th Edition. Volume 1. 01/2008:2.2.32., pp. 51, 2010.

[23] R. Bobinait, P. Viškelis, and P. R. Venskutonis, "Variation of total phenolics, anthocyanins, ellagic acid and radical scavenging capacity in various raspberry (Rubus spp.) cultivars," Food Chemistry, vol. 132, no. 3, pp. 1495-1501, 2012.

[24] W. Brand-Williams, M. E. Cuvelier, and C. Berset, "Use of a free radical method to evaluate antioxidant activity," LWT - Food Science and Technology, vol. 28, no. 1, pp. 25-30, 1995.

[25] R. Re, N. Pellegrini, A. Proteggente, A. Pannala, M. Yang, and C. Rice-Evans, "Antioxidant activity applying an improved ABTS radical cation decolorization assay," Free Radical Biology \& Medicine, vol. 26, no. 9-10, pp. 1231-1237, 1999.

[26] I. F. F. Benzie and J. J. Strain, "Ferric reducing/antioxidant power assay: direct measure of total antioxidant activity of biological fluids and modified version for simultaneous measurement of total antioxidant power and ascorbic acid concentration," Methods in Enzymology, vol. 299, pp. 15-27, 1999.

[27] J. Dai and R. J. Mumper, "Plant phenolics: extraction, analysis and their antioxidant and anticancer properties," Molecules, vol. 15, no. 10, pp. 7313-7352, 2010.

[28] J. Azmir, I. S. M. Zaidul, M. M. Rahman et al., "Techniques for extraction of bioactive compounds from plant materials: a review," Journal of Food Engineering, vol. 117, no. 4, pp. 426-436, 2013.

[29] T. V. Ngo, C. J. Scarlett, M. C. Bowyer, P. D. Ngo, and Q. V. Vuong, "Impact of different extraction solvents on bioactive compounds and antioxidant capacity from the root of Salacia chinensis L, Journal of Food Quality, vol. 2017, Article ID 9305047, 2017.

[30] N. Kumar, P. Bhandari, B. Singh, A. P. Gupta, and V. K. Kaul, "Reversed phase-HPLC for rapid determination of polyphenols in flowers of rose species," Journal of Separation Science, vol. 31, no. 2, pp. 262-267, 2008.

[31] K. Robards, "Strategies for the determination of bioactive phenols in plants, fruit and vegetables," Journal of Chromatography A, vol. 1000, no. 1-2, pp. 657-691, 2003.

[32] E. de Rijke, P. Out, W. M. A. Niessen, F. Ariese, C. Gooijer, and U. A. T. Brinkman, "Analytical separation and detection methods for flavonoids," Journal of Chromatography A, vol. 1112, no. 1-2, pp. 31-63, 2006.

[33] A. Escarpa and M. C. González, "Evaluation of high-performance liquid chromatography for determination of phenolic compounds in pear horticultural cultivars," Chromatographia, vol. 51, no. 1-2, pp. 37-43, 2000.

[34] ICH Harmonised Tripartite Guideline, "Validation of Analytical Procedures: Text and Methodology Q2 (R1)," in Proceedings of the International Conference on Harmonisation of Technical Requirements for Registration of Pharmaceuticals for Human Use, 1994.

[35] Y. Sato, S. Itagaki, T. Kurokawa et al., "In vitro and in vivo antioxidant properties of chlorogenic acid and caffeic acid," International Journal of Pharmaceutics, vol. 403, no. 1-2, pp. 136138, 2011.

[36] X. Zhang, H. Huang, T. Yang et al., "Chlorogenic acid protects mice against lipopolysaccharide-induced acute lung injury," Injury, vol. 41, no. 7, pp. 746-752, 2010.

[37] T. Thomas and A. F. Pfeiffer, "Foods for the prevention of diabetes: How do they work?" Diabetes/Metabolism Research and Reviews, vol. 28, no. 1, pp. 25-49, 2012.

[38] Y. Kanno, R. Watanabe, H. Zempo, M. Ogawa, J. Suzuki, and M. Isobe, "Chlorogenic acid attenuates ventricular remodeling after myocardial infarction in mice," International Heart Journal, vol. 54, no. 3, pp. 176-180, 2013.

[39] N. Cinkilic, S. K. Cetintas, T. Zorlu et al., "Radioprotection by two phenolic compounds: chlorogenic and quinic acid, on $\mathrm{X}$-ray induced DNA damage in human blood lymphocytes in vitro," Food and Chemical Toxicology, vol. 53, pp. 359-363, 2013.

[40] B. Stefanska, H. Karlic, F. Varga, K. Fabianowska-Majewska, and A. G. Haslberger, "Epigenetic mechanisms in anti-cancer actions of bioactive food components-the implications in cancer prevention," British Journal of Pharmacology, vol. 167, no. 2, pp. 279-297, 2012.

[41] J. Kolniak-Ostek and J. Oszmiański, "Characterization of phenolic compounds in different anatomical pear (Pyrus communis L.) parts by ultra-performance liquid chromatography photodiode detector-quadrupole/time of flight-mass spectrometry (UPLC-PDA-Q/TOF-MS)," International Journal of Mass Spectrometry, vol. 392, pp. 154-163, 2015.

[42] L.-Z. Lin and J. M. Harnly, "Phenolic compounds and chromatographic profiles of pear skins (Pyrus spp.)," Journal of Agricultural and Food Chemistry, vol. 56, no. 19, pp. 9094-9101, 2008.

[43] A. Schieber, P. Keller, and R. Carle, "Determination of phenolic acids and flavonoids of apple and pear by high-performance liquid chromatography," Journal of Chromatography A, vol. 910, no. 2, pp. 265-273, 2001.

[44] D. Tanriöven and A. Ekşi, "Phenolic compounds in pear juice from different cultivars," Food Chemistry, vol. 93, no. 1, pp. 8993, 2005.

[45] F. Dajas, "Life or death: neuroprotective and anticancer effects of quercetin," Journal of Ethnopharmacology, vol. 143, no. 2, pp. 383-396, 2012.

[46] M. González-Vallinas, M. González-Castejón, A. RodríguezCasado, and A. Ramírez de Molina, "Dietary phytochemicals in cancer prevention and therapy: a complementary approach with promising perspectives," Nutrition Reviews, vol. 71, no. 9, pp. 585-599, 2013.

[47] N. Balasuriya and H. P. V. Rupasinghe, "Antihypertensive properties of flavonoid-rich apple peel extract," Food Chemistry, vol. 135, no. 4, pp. 2320-2325, 2012.

[48] L. Raudone, R. Raudonis, M. Liaudanskas, V. Janulis, and P. Viskelis, "Phenolic antioxidant profiles in the whole fruit, flesh and peel of apple cultivars grown in Lithuania," Scientia Horticulturae, vol. 216, pp. 186-192, 2017. 
[49] M. A. Olszewska and P. Michel, "Antioxidant activity of inflorescences, leaves and fruits of three sorbus species in relation to their polyphenolic composition," Natural Product Research (Formerly Natural Product Letters), vol. 23, no. 16, pp. 1507-1521, 2009. 

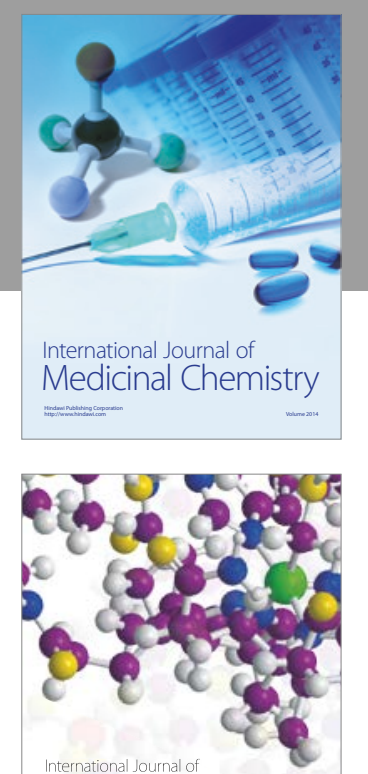

Carbohydrate Chemistry

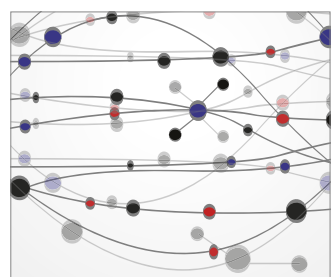

The Scientific World Journal
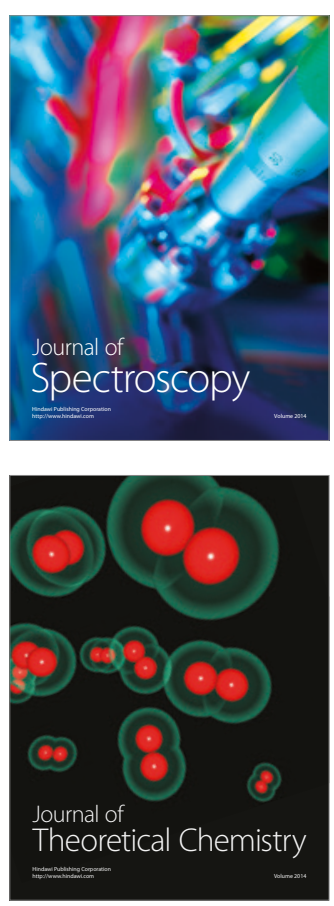
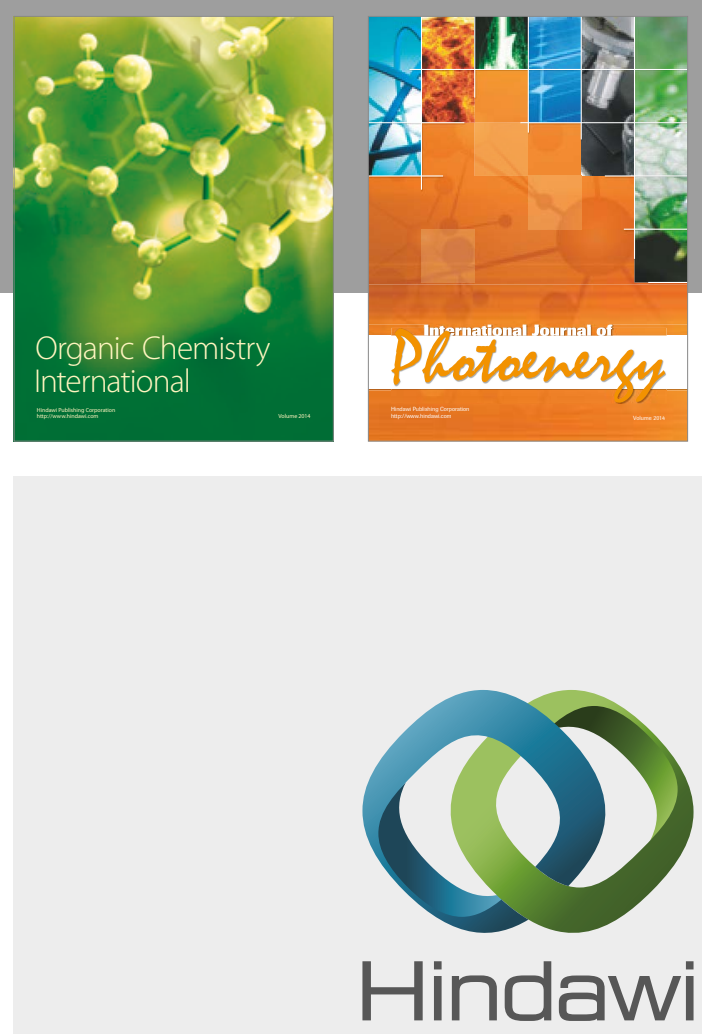

Submit your manuscripts at

https://www.hindawi.com

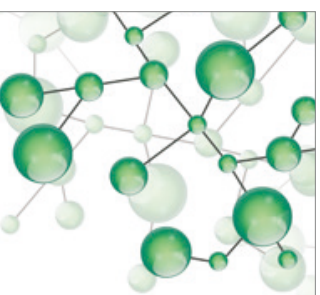

International Journal of

Inorganic Chemistry

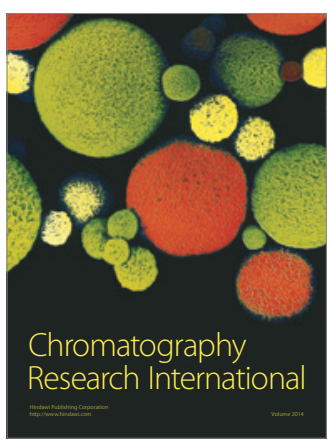

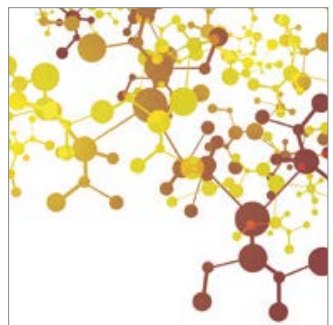

Applied Chemistry
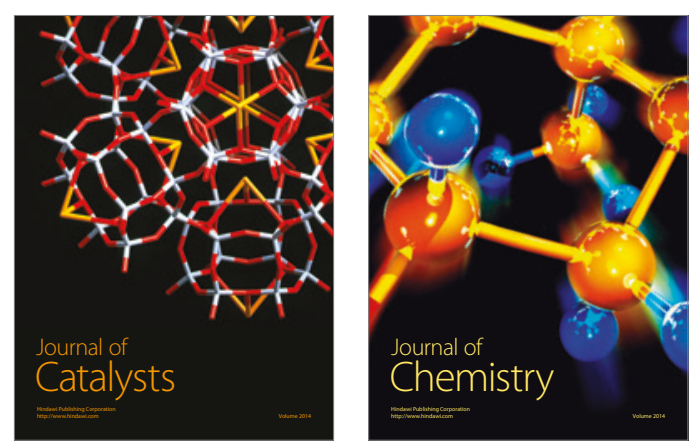
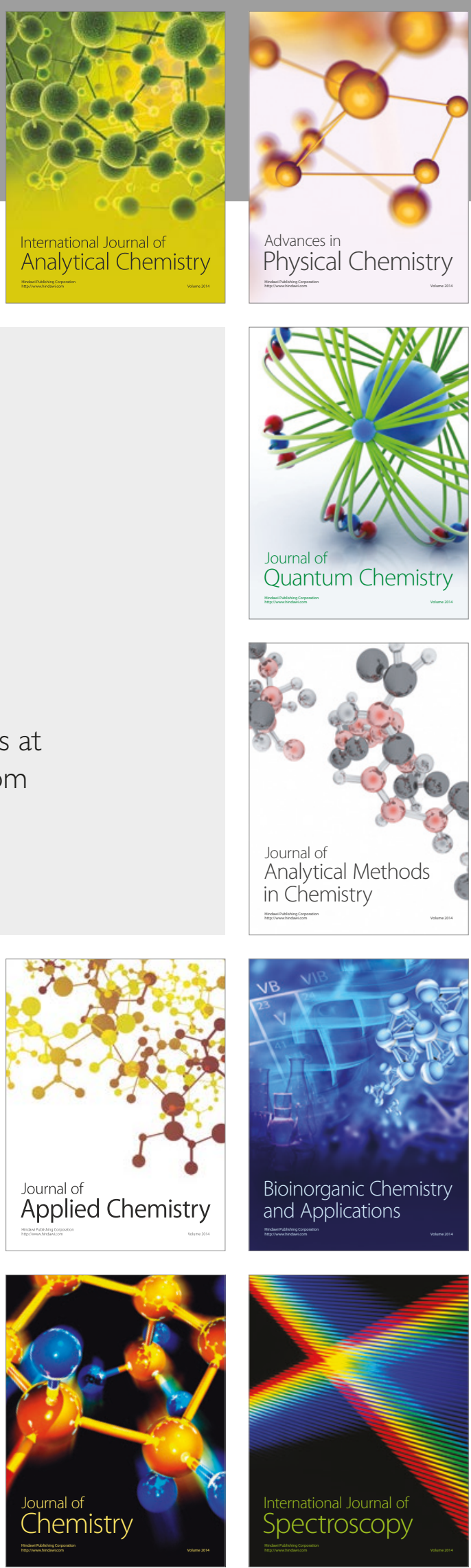